\title{
Resumption of Cyclic Ovarian Activity by Herbal Preparation AyuFertin in Bulgarian Murrah Buffaloes at Early Postpartum
}

\author{
Yordanka Ilieva ${ }^{1}$, Nasko Vasilev ${ }^{2}$, Ivan Fasulkov ${ }^{2}{ }^{-}$, Pencho Penchev ${ }^{1}$, Desislava Abadjieva ${ }^{3}(\mathbb{D}$, \\ Vanya Mladenova $^{3}$, Ayla Ilyazova ${ }^{4}$, Dasha Mihaylova ${ }^{5}\left(\mathbb{D}\right.$, Stanimir Yotov ${ }^{2}$ and Elena Kistanova ${ }^{3, *(1)}$ \\ 1 Agricultural Institute-Shumen, AA, 9700 Shumen, Bulgaria; jordani64@abv.bg (Y.I.); \\ pen.penchev@gmail.com (P.P.) \\ 2 Department Obstetrics, Reproduction and Reproductive Disorders, Faculty of Veterinary Medicine, \\ Trakia University, 6000 Stara Zagora, Bulgaria; nasvas@abv.bg (N.V.); i.fasulkov@gmail.com (I.F.); \\ stanrad@abv.bg (S.Y.) \\ 3 Institute of Biology and Immunology of Reproduction, Bulgarian Academy of Sciences, 1113 Sofia, Bulgaria; \\ dessi_1@abv.bg (D.A.); vanya_mladenova@abv.bg (V.M.) \\ 4 Department of Microbiology, University of Food Technologies, 4002 Plovdiv, Bulgaria; ayla_ilyazova@abv.bg \\ 5 Department of Biotechnology, University of Food Technologies, 4002 Plovdiv, Bulgaria; \\ dashamihaylova@yahoo.com \\ * Correspondence: kistanova@gmail.com; Tel.: +35-989-822-5520
}

check for

updates

Citation: Ilieva, Y.; Vasilev, N.; Fasulkov, I.; Penchev, P.; Abadjieva, D.; Mladenova, V.; Ilyazova, A.; Mihaylova, D.; Yotov, S.; Kistanova, E. Resumption of Cyclic Ovarian Activity by Herbal Preparation AyuFertin in Bulgarian Murrah Buffaloes at Early Postpartum. Animals 2021, 11, 420. https:// doi.org/10.3390/ani11020420

Academic Editor: Raffaele Boni

Received: 23 December 2020

Accepted: 2 February 2021

Published: 6 February 2021

Publisher's Note: MDPI stays neutral with regard to jurisdictional claims in published maps and institutional affiliations.

Copyright: (c) 2021 by the authors. Licensee MDPI, Basel, Switzerland. This article is an open access article distributed under the terms and conditions of the Creative Commons Attribution (CC BY) license (https:// creativecommons.org/licenses/by/ $4.0 /)$.
Simple Summary: Shortening the inter-calving interval is the most important problem in buffalo breeding, especially on organic farms, where the use of hormones is prohibited. The demand for herbal preparations that stimulate the activity of ovaries, as well as the choice of an appropriate time for their application, remains essential today. This study provides the results of the positive effect of the herbal product, which identified a wide range of bioactive substances-carotenoids, flavonoids, and fatty acids, including esters of trienoic fatty acids, on the resumption of the cyclic ovarian activity in early postpartum buffaloes. Overcoming postpartum anestrus in buffaloes is highly cost-effective due to cost savings for keeping dry, unproductive animals.

Abstract: This study evaluates the phytochemical composition and ability of herbal preparation AyuFertin, supplemented shortly after calving, to resume the cyclic ovarian activity in postpartum Bulgarian Murrah buffaloes. In total, 13 healthy Bulgarian Murrah buffaloes at the age of 4-10 years, calved in March-April 2019 were involved in the experiment. Seven experimental buffaloes were treated individually per os with AyuFertin according to producer instruction. All animals were subjected to regular ultrasound examination of ovaries. GC-MS analysis of fatty acids composition and HPLC-DAD analysis of carotenoid and tocopherol content in AyuFertin were conducted. The determination of estrus occurrence and natural mating were done by a fertile bull. The development of the large follicles $(12.5-14.3 \mathrm{~mm})$ in $85.7 \%$ of treated animals was observed on day 24 postpartum compared to $0 \%$ in controls. Clinical signs of estrus were recorded in $71.4 \%$ of the animals, followed by an $80 \%$ pregnancy rate versus $16 \%$ in controls within 70 days after calving. In conclusion, the supplementation of the bioactive herbal product AyuFertin from day 21 postpartum can stimulate the follicular growth in the buffalo's ovary, which leads to the development of follicles with ovulatory capacity, followed by successful ovulation. The above-mentioned treatment resulted in a better pregnancy rate in the treated multiparous compared to the control buffaloes bred by natural service.

Keywords: postpartum buffalo; AyuFertin treatment; ovarian activity

\section{Introduction}

Due to low reproductive efficiency, overcoming the postpartum anestrus and shortening the inter-calving interval are the most important problems in buffalo breeding. These challenges cause heavy economic losses related to the cost of keeping dry, unproductive 
animals. The application of hormonal therapy for this purpose provides good results [1-3]. However, other than the high cost, the frequent use of exogenous hormones can impair the reproductive system of animals and lead to increased levels of sex hormones in milk, which affects consumer health [4-6]. In addition, in organic farms, the use of hormones is prohibited. Several herbal protocols instead of hormones or in combination with them have been developed for buffaloes to overcome the postpartum anestrus [7]. However, the main effort has been focused on the long-time postpartum anestrus-more than six months. Some authors report about the positive effect of Prajana HS, a commercial nonhormonal herbal preparation that affords optimization of ovarian functions and thus induces timely estrus, ovulation, and conception in treated buffaloes with true postpartum anestrus (6-8 months after calving) compared to the control, Prajana-free animals [8-10]. According to Chaudhiry et al. [11], the plants Randia dumetorum (fruit) and Tinospora cordifolia (stem) and their combination have an effective role in the treatment of anoestrus buffalo heifers. These plants induced estrus in more than $80 \%$ of the treated animals and were more effective than Prajana HS [11]. The mixture of Abroma augusta (root) and Nigella sativa (seed) in a 2:1 ratio also provoked a 50\% estrus response in anoestrus buffaloes [12]. Murraya koenigii and Aegle marmelos have also shown a positive effect on overcoming the anestrus in buffaloes. After nine days of treatment, estrus was induced in $60 \%(6 / 10)$ of the animals followed by $66.67 \%(4 / 6)$ pregnancy [13].

The used herbs contain various biologically active substances with a positive effect on the reproductive system [10]. Among them, the role of the specific fatty acids involved in the biosynthesis of prostaglandins is important. Prostaglandins (PG), belonging to the eicosanoids group, are 20-carbon unsaturated hydroxyl fatty acids with a cyclopentane ring. The main precursor of PG, the arachidonic acid, is a product of the conversion of the linoleic essential fatty acid [14]. According to the literature, inadequate production of endogenous prostaglandin in the postpartum period leads to delay in uterine involution $[15,16]$. At the same time, the administration of prostaglandin F2-alfa in the early postpartum leads to accelerated uterine involution, to resumption of the fertile ovarian cyclicity, and to increased conception rate of first service [17-19].

The herbal preparation AyuFertin, suggested for heat induction in animals, includes the following herbs: Piper longum, Piper nigrum, Zingiber officinale, Citrullus colocynthis, which are well known in alternative medicine as substances with antioxidant, anti-inflammatory, and immunomodulatory properties [20]. Recent data show that these herbs contain various fatty acids [21,22].

Scientific data on the use of herbal preparations with natural prostaglandin precursors in the early stages of postpartum in buffaloes are very scarce, especially for AyuFertin herbal preparation, for which it is completely lacking. Our study aimed to investigate the phytochemical composition of AyuFertin and evaluate its effect when supplemented shortly after calving on the ovarian activity in the postpartum Bulgarian Murrah buffaloes.

\section{Materials and Methods}

\subsection{Analysis of the AyuFertin Phytochemical Composition \\ 2.1.1. Carotenoid and Tocopherol Contents Evaluation}

Qualitative and quantitative determinations of carotenoids and tocopherols were performed by using Elite LaChrome (Hitachi, Tokyo, Japan) high-performance liquid chromatography (HPLC) system equipped with diode array detector (DAD) and ELITE LaCHrome (Hitachi, Tokyo, Japan) software. The content of carotenoids was analyzed by the method of Georgieva et al. [23] with some modifications and the tocopherol content was assessed by the method described by Mihaylova et al. [24]. The results for both assays were expressed as $\mu \mathrm{g} / \mathrm{g}$ dry weight $(\mathrm{dw})$. 
2.1.2. Total Polyphenolic Content (TPC), Total Flavonoid Content (TFC), and Antioxidant Activity Evaluation

Representative samples of four grams of AyuFertin (randomly selected from four packages each of $500 \mathrm{~g}$ ) were added to $20 \mathrm{~mL}$ of $80 \%$ methanol and sonicated at a frequency of $35 \mathrm{kHz}$ with a maximum input power of $240 \mathrm{~W}$, for $60 \mathrm{~min}$, at $30^{\circ} \mathrm{C}$ (UST 5.7150 Siel, Gabrovo, Bulgaria). The obtained extracts were filtered and stored at $4{ }^{\circ} \mathrm{C}$ without adding any preservatives until analyses.

Evaluation of Total Polyphenolic and Total Flavonoid Contents

The total polyphenolic content was analyzed following the method of Kujala et al. [25] with some modifications [26]. The TPC was expressed as mg gallic acid equivalents (GAE) per g dry weight $(\mathrm{dw})$.

The total flavonoid content was evaluated according to the method described by $\mathrm{Mi}$ haylova et al. [26] and the results were expressed as mg quercetin equivalents (QE)/g dw.

Determination of Antioxidant Activity

$D P P H^{\bullet}$ Radical Scavenging Assay

The ability of the sample to donate an electron and scavenge 2,2-diphenil-1-picrylhydrazyl (DPPH) radical was determined by the slightly modified method of Brand-Williams et al. [27] as described by Mihaylova et al. [26]. The DPPH radical scavenging activity was presented as a function of the concentration of Trolox-Trolox equivalent antioxidant capacity (TEAC) and was defined as the concentration Trolox having equivalent antioxidant activity expressed as the $\mu \mathrm{M}$ per $\mathrm{g} d w(\mu \mathrm{M} \mathrm{TE} / \mathrm{g} \mathrm{dw})$.

ABTS $^{\bullet+}$ Radical Scavenging Assay

The radical scavenging activity of the sample against 2,2'-azino-bis (3-ethylbenzothiazoline6-sulfonic acid) $\left(\mathrm{ABTS}^{\bullet+}\right)$ was estimated according to Re et al. [28] and the results were expressed as TEAC value ( $\mu \mathrm{M}$ TE/g dw).

Ferric-Reducing Antioxidant Power (FRAP) Assay

The FRAP assay was carried out according to the procedure of Benzie and Strain [29] and the results were expressed as $\mu \mathrm{M} \mathrm{TE} / \mathrm{g} \mathrm{dw}$.

Cupric ion Reducing Antioxidant Capacity (CUPRAC) Assay

The CUPRAC assay was carried out according to the procedure described by Apak et al. [30]. The results were expressed as $\mu \mathrm{M} \mathrm{TE} / \mathrm{g} \mathrm{dw}$.

\subsubsection{Gas-Chromatographic-Mass-Spectral (GC-MS) Analysis of Fatty Acids Composition}

The extraction of the fatty acids was carried out by means of diethyl ether in a Soxhlet apparatus following the AOAC Method 920.39 [31]. The fatty acids methyl esters (FAMEs) were prepared in accordance with ISO 12966-2:2017 [32]. GC-MS analysis of the whole fatty acid content was performed using a Thermo Scientific GC-MS system (Thermo Scientific, Waltham, MA, USA) comprising an AI/AS 1310 auto-sampler and a Gas Chromatograph (Trace 1300) interfaced to an ISQ mass spectrometer, equipped with a TR-5MS fused silica capillary column $(30 \mathrm{~m} \times 0.25 \mathrm{~mm}$, ID $0.25 \mu \mathrm{m})$. For GC-MS detection, electron impact mode was used. Mass spectra were taken at $70 \mathrm{eV}$, a scan interval of $0.2 \mathrm{~s}$, and $\mathrm{m} / \mathrm{z}$ range 46 to $650 \mathrm{Da}$. Helium gas was used as a carrier gas at a constant flow rate of $1 \mathrm{~mL} / \mathrm{min}$, and an injection volume of $1 \mu \mathrm{L}$ was employed (a split ratio of 1:25). The MS transfer line temperature was set to $260^{\circ} \mathrm{C}$ and the ion-source temperature was $220^{\circ} \mathrm{C}$. The oven temperature was programmed from $110^{\circ} \mathrm{C}$ (held for $3 \mathrm{~min}$ ), with an increase of $10^{\circ} \mathrm{C} / \mathrm{min}$ to $220^{\circ} \mathrm{C}$, held for $6 \mathrm{~min}$, then $15^{\circ} \mathrm{C} / \mathrm{min}$ to $310^{\circ} \mathrm{C}$ and held for $5 \mathrm{~min}$. The injector temperature was maintained at $240^{\circ} \mathrm{C}$. The identification of the individual FAMEs was made by comparison of their mass spectra with the NIST standard reference database. Quantification of the identified fatty acids was made by the area normalization method (represented as \% of the area of total fatty acids in the sample). 


\subsection{Animals Management and Experimental Design}

The experiment was conducted in 13 clinically healthy postpartum Bulgarian Murrah buffaloes aged between 4 and 10 years with an average body weight of $580 \pm 15.1 \mathrm{~kg}$, calved in March-April and housed on the farm of Agricultural Institute-Shumen, Bulgaria. The animals were allotted two groups, control $(n=6)$ and experimental $(n=7)$ by the analog method, regarding body condition, and included both primiparous and multiparous buffaloes. The experiment was carried out during March-July, 2019.

The farming system was intensive- -tie-stalls with exercise yard. All animals received the standard daily diet for dairy buffaloes. The ration components were as follows: wheat $15 \%$, barley $12 \%$, corn $56 \%$, wheat bran $10 \%$, sunflower oilcake $5 \%$, dicalcium phosphate $0.6 \%$ salt $0.4 \%$, and chalk $1 \%$, providing $1629 \mathrm{kcal}$ energy and $96 \mathrm{~g}$ digestible protein. Water intake was ad libitum.

The experiment was scheduled to start on day 21 after calving (Figure 1). The protocol included a three-day supplementation period and a secondary three-day supplementation if the individual buffalo did not express clinical signs of estrus and acceptance of bull within 10 days after the first treatment onset. The experimental animals were administered orally with feed supplement AyuFertin, containing powdered dried herbs (Indian Herbs Specialities Pvt. Ltd, Saharanpur, India), for three consecutive days in the dose of $3 \mathrm{~g} / 100 \mathrm{~kg}$ body weight in accordance with the producer's instructions from day 21 postpartum $(\mathrm{d} \mathrm{pp})$ in the first supplementation period and from $31 \mathrm{~d} p p$ in the secondary one. From $21 \mathrm{~d} p \mathrm{p}$, a fertile bull was introduced in both groups. Permanent observations for the presence of estrus and/or natural mating from bull were recorded until the end of the experiment.

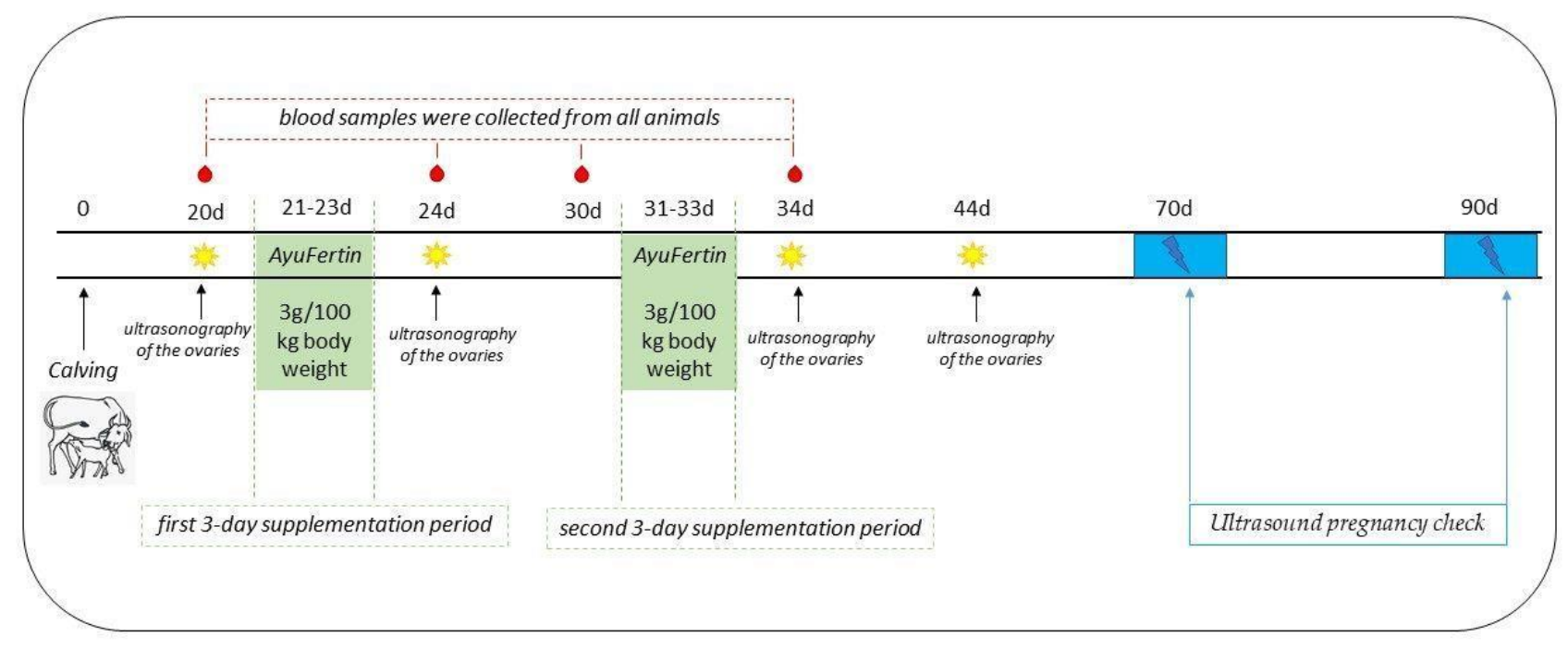

Figure 1. Scheme of the experimental design.

The ultrasonography (USG) of the ovaries of all animals was performed on $20 \mathrm{~d} p \mathrm{p}$, after the end of the first (24d pp) and second supplementation periods ( $34 \mathrm{~d} \mathrm{pp}$ ) and 10 days after the end of the second supplementation period ( $44 \mathrm{~d} \mathrm{pp})$. Ultrasound pregnancy check was carried out on days 70pp and 90pp. Transrectal ultrasonography was performed with a SonoScape A2 Vet (SonoScape Co. Ltd., Shenzhen, China), a multi-frequency (7-12 MHz) linear probe and transrectal approach. During the ovarian USG, the number and size of follicles and presence of a corpus luteum in one of the ovaries were registered.

The experimental work with animals on the farm was approved by the Bulgarian National Animal Ethics commission in accordance with the Bulgarian Veterinary Law $(25 / 01 / 2011)$ regarding the living conditions and welfare of livestock animals used for experimental purposes, which is adapted to the European Union regulation 86/609 (AF 9747A-0002/N1430 from 05 April 2018). 


\subsection{Biochemical and Progesterone Analysis}

The blood samples were collected from the jugular vein of all animals before (days 20 and 30) and after supplementations with AyuFertin (days 24 and 34) in vacuum blood collection tubes. After that, the samples were centrifuged, and the serum was separated in sterile Eppendorf tubes and stored at $-20{ }^{\circ} \mathrm{C}$ until the time of analysis. The serum was analyzed for biochemical profiles including total protein (TP), blood glucose, total cholesterol (TChol), lactate dehydrogenase (LDH), and alkaline phosphatase enzymes (ALP). The evaluation of the mentioned parameters was performed using the standard kits for biochemical analyzer Mindray BA-88A (Mindray Bio-Medical Electronics Co, Ltd. Shenzhen, Nanshan, China).

The serum progesterone concentration was determined by the EIA method using the kit Progesterone EIA 96 TEST (Linear Chemicals, Spain). The intra-assay coefficient of variances ranged from $2.2 \%$ to $7.1 \%$ and the inter-assay coefficient of variance was $2.6 \%$ to $12.6 \%$ for four repeated measurements.

\subsection{Statistical Analysis}

Due to the small number of used animals, the non-parametric statistic was applied. The results were analyzed using the software product Stat.Soft, v.10 (StatSoft Inc., Tulsa, OK, USA). The significance of the mean difference was defined by the non-parametric Mann-Whitney test. To compare the pregnancy rate between primiparous and multiparous animals, chi-square test for proportions with small samples was used [33]. The differences were considered significant at $p<0.05$. The data are presented as a mean \pm standard deviation (SD).

\section{Results}

\subsection{Phytochemical Composition of AyuFertin}

AyuFertin's phytochemical analysis showed that it contained bioactive substances such as carotenoids, tocopherols, flavonoids, and fatty acids. Among the carotenoids and tocopherols found in the AyuFertin supplement, the distribution of $\delta$-tocopherol, $\alpha$-tocopherol, and lutein was determined (Table 1) with a predominance of $\alpha$-tocopherol.

Table 1. Tocopherols ( $\mu \mathrm{g} / \mathrm{g} \mathrm{dw})$ and carotenoids $(\mu \mathrm{g} / \mathrm{g} \mathrm{dw}$ ) content of AyuFertin.

\begin{tabular}{cc}
\hline Sample/Assay & AyuFertin \\
\hline Tocopherols, $\mu \mathrm{g} / \mathrm{g} \mathrm{dw}$ & \\
$\delta$-tocopherol, & $6.37 \pm 0.51$ \\
$\alpha$-tocopherol & $22.87 \pm 1.11$ \\
Y-tocopherol & n.d \\
Carotenoids, $\mu \mathrm{g} / \mathrm{g} \mathrm{dw}$ & $5.51 \pm 0.45$ \\
lutein & n.d \\
lycopene & n.d \\
\hline
\end{tabular}

*n.d-not detected.

The established TPC and TFC in AyuFertin are a prerequisite for the antioxidant potential of the herbal preparation (Table 2).

The total lipid content was found to be $20.93 \%$ and the presence of trienoic fatty acid esters in addition to palmitic acid, linoleic acid, oleic acid, stearic acid, and palmitic monoglyceride was found (Table 3). 
Table 2. Total polyphenolic content (TPC, mg GAE/g dw), total flavonoid content (TFC, mg QE/g $\mathrm{dw})$, and in vitro antioxidant activity ( $\mu \mathrm{M} \mathrm{TE} / \mathrm{g} \mathrm{dw})$ of AyuFertin.

\begin{tabular}{cc}
\hline Sample/Assay & AyuFertin \\
\hline Total polyphenolic content, $\mathrm{mg} \mathrm{GAE} / \mathrm{g} \mathrm{dw}$ & $21.00 \pm 0.93$ \\
Total flavonoid content, $\mathrm{mg} \mathrm{QE} / \mathrm{g} \mathrm{dw}$ & $319.62 \pm 9.83$ \\
In vitro antioxidant activity, $\mu \mathrm{M} \mathrm{TE} / \mathrm{g} \mathrm{dw}$ & \\
ABTS & $191.66 \pm 2.52$ \\
DPPH & $209.25 \pm 1.71$ \\
FRAP & $334.28 \pm 0.70$ \\
CUPRAC & $331.27 \pm 5.94$ \\
\hline
\end{tabular}

Table 3. Total lipid content and fatty acids composition of AyuFertin.

\begin{tabular}{|c|c|c|c|}
\hline Apex RT & Area & $\%$ Area & Fatty Acids \\
\hline 14.76 & $77,575,835$ & 8.81 & Palmitic acid \\
\hline 17.23 & $371,305,357$ & 42.15 & Linoleic acid \\
\hline 17.32 & $253,137,987$ & 28.73 & Oleic acid \\
\hline 17.77 & $46,436,988$ & 5.27 & Stearic acid \\
\hline 20.38 & $67,170,678$ & 7.62 & \multirow{4}{*}{$\begin{array}{c}\mathrm{CH}_{3} \text { esters with } \mathrm{Mw} \text { 292: } \\
\text { 6-cis,9-cis,11-trans-octadecatrienoate } \\
\text { 9.cis.,11.trans.t,13.trans.-octadecatrienoate } \\
\text { 9,12,15-Octadecatrienoic } \\
\text { acidGamma-Linolenic acid }\end{array}$} \\
\hline 20.54 & $22,680,426$ & 2.57 & \\
\hline 20.84 & $15,537,705$ & 1.76 & \\
\hline 21.29 & $21,773,425$ & 2.47 & \\
\hline 24.2 & $3,012,782$ & 0.34 & Palmitin monoglyceride \\
\hline $\begin{array}{c}\text { Total lipid } \\
\text { content }\end{array}$ & & 20.93 & \\
\hline
\end{tabular}

\subsection{Effect of AyuFertin on the Blood Parameters}

The main biochemical parameters of the blood did not differ significantly between the control and experimental groups at the beginning of the experiment (Table 4). AyuFertin treatment reduces the total serum cholesterol of the supplemented animals. The activity of the lactate dehydrogenase enzyme was enhanced, while the alkaline phosphatase did not change (Table 4).

Table 4. Biochemical parameters in the blood serum of control and treated with AyuFertin Bulgarian Murrah buffaloes.

\begin{tabular}{|c|c|c|c|c|c|}
\hline \multirow{2}{*}{ Group } & \multicolumn{5}{|c|}{ Biochemical Parameters } \\
\hline & $\begin{array}{c}\text { TP } \\
\mathrm{g} / \mathrm{dL}\end{array}$ & $\begin{array}{l}\text { Glucose } \\
\mathrm{mg} / \mathrm{dL}\end{array}$ & $\begin{array}{l}\text { TChol } \\
\mathrm{mg} / \mathrm{dL}\end{array}$ & $\begin{array}{l}\text { LDH } \\
\text { U/L }\end{array}$ & $\begin{array}{l}\text { ALP } \\
\text { U/L }\end{array}$ \\
\hline \multicolumn{6}{|l|}{ Control $(n=6)$} \\
\hline & $6.5 \pm 0.78^{a}$ & $38.7 \pm 3.2^{\mathrm{a}}$ & $161.5 \pm 5.03^{a}$ & $527.3 \pm 23.26^{a}$ & $188.5 \pm 14.54^{\mathrm{a}}$ \\
\hline \multicolumn{6}{|l|}{$\begin{array}{l}\text { Experimental } \\
\quad(n=7)\end{array}$} \\
\hline $\operatorname{BFT}(n=7)$ & $5.9 \pm 0.47^{b}$ & $36.1 \pm 2.32^{b}$ & $157 \pm 8.45^{b}$ & $550 \pm 34.4^{b}$ & $178 \pm 12.05^{b}$ \\
\hline $\operatorname{AFT}(n=7)$ & $5.4 \pm 0.49^{c}$ & $38.4 \pm 2.51^{\mathrm{c}}$ & $142.7 \pm 4.42^{\mathrm{bc}}$ & $560 \pm 47.1^{c}$ & $177.3 \pm 16.47^{c}$ \\
\hline $\operatorname{BST}(n=5)$ & $5.4 \pm 0.28^{\mathrm{d}}$ & $38.3 \pm 2.48^{\mathrm{d}}$ & $147 \pm 4.78^{\mathrm{bd}}$ & $592 \pm 16.75^{b d}$ & $169.4 \pm 17.7^{\mathrm{d}}$ \\
\hline $\operatorname{AST}(n=5)$ & $6.8 \pm 0.87^{\mathrm{e}}$ & $36.9 \pm 2.20^{\mathrm{e}}$ & $153.4 \pm 10.89^{\mathrm{e}}$ & $628.3 \pm 44.51$ be & $177.8 \pm 16.16^{\mathrm{e}}$ \\
\hline
\end{tabular}


The average progesterone level on day 21 did not differ significantly between the control and experimental groups $(1.3 \pm 1.55 \mathrm{ng} / \mathrm{mL}$ and $1.6 \pm 1.75 \mathrm{ng} / \mathrm{mL}$, respectively) The supplemented animals had a decreasing dynamic of progesterone after the treatments (Figure 2). The level of progesterone after the first supplementation decreased significantly $(p<0.01)$ compared to the pre-treatment period, while the decrease after the second AyuFertin treatment was not significant.

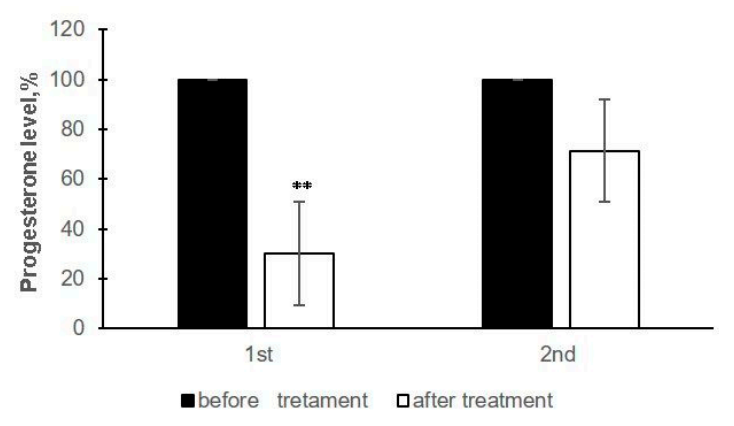

Figure 2. Relative change of progesterone level in blood serum of experimental Bulgarian Murrah buffaloes according to the number of treatments with AyuFertin supplement. The progesterone level before the first and second treatments was accepted as $100 \%$. ${ }^{* *} p<0.01$ compared to pretreatment period.

\subsection{Effect of AyuFertin on the Ovarian Activity}

The ovarian state of animals in both groups was similar on $20 \mathrm{~d}$ pp (Table 5). In the control group, the number of small follicles did not change significantly with the advance of postpartum days, but the number of medium follicles enhanced more than twice. No large follicles were detected until day 24 pp (Figure S1). In this group, the presence of both, a large follicle and a corpus luteum, was found only on $44 \mathrm{~d} p \mathrm{p}$ in one animal. This animal came in heat and was served by the bull.

Table 5. Ovarian structures, estrus expression, and pregnancy rate in control and experimental Bulgarian Murrah buffaloes.

\begin{tabular}{|c|c|c|c|c|c|c|c|c|}
\hline \multirow{2}{*}{$\begin{array}{c}\text { Parameters } \\
\text { Postpartum days }\end{array}$} & \multicolumn{4}{|c|}{ Control Group $(n=6)$} & \multicolumn{4}{|c|}{ Experimental Group $(n=7)$} \\
\hline & 20 & 24 & 34 & 44 & 20 & 24 & 34 & 44 \\
\hline \multicolumn{9}{|l|}{ Ovarian structures } \\
\hline $\begin{array}{l}\text { Small follicles } \\
(<6 \mathrm{~mm}) \%(n)\end{array}$ & $100(6 / 6)$ & $100(6 / 6)$ & $100(6 / 6)$ & $100(6 / 6)$ & $100(7 / 7)$ & $42.8(3 / 7)$ & $60(3 / 5)$ & $100(7 / 7)$ \\
\hline $\begin{array}{l}\text { Medium follicles } \\
(6-9 \mathrm{~mm}) \%(n)\end{array}$ & $33.4(2 / 6)$ & $33.4(2 / 6)$ & $83.3(5 / 6)$ & $100(6 / 6)$ & $42.8(3 / 7)$ & $42.8(3 / 7)$ & $100(5 / 5)$ & $100(7 / 7)$ \\
\hline $\begin{array}{l}\text { Large follicles } \\
(\geq 10 \mathrm{~mm}) \%(n)\end{array}$ & $0(0 / 6)$ & $0(0 / 6)$ & $16.6(1 / 6)$ & $33.4(2 / 6)$ & $0(0 / 7)$ & $85.7(6 / 7)$ & $80(4 / 5)$ & $71.4(5 / 7)$ \\
\hline Corpus luteum \% $(n)$ & $0(0 / 6)$ & $0(0 / 6)$ & $0(0 / 6)$ & $16.6(1 / 6)$ & $0(0 / 7)$ & $14.2(1 / 7)$ & $60(3 / 5)$ & $42.8(3 / 7)$ \\
\hline \multicolumn{9}{|l|}{$\begin{array}{l}\text { Recorded estrus with } \\
\text { bull mating } \%(n)\end{array}$} \\
\hline $\begin{array}{l}\text { After 1st treatment } \\
\text { After 2nd treatment }\end{array}$ & $16.6(1 / 6)$ & & & & $\begin{array}{l}28.6(2 / 7) \\
60.0(3 / 5)\end{array}$ & & & \\
\hline $\begin{array}{c}\text { Total } \\
\text { Pregnancy rate, \% (n) }\end{array}$ & $16.6(1 / 6)$ & & & & $71.4(5 / 7)$ & & & \\
\hline $\begin{array}{l}\text { Day } 70 \\
\text { Day } 90\end{array}$ & $\begin{array}{l}16.6(1 / 6) \\
16.6(1 / 6)\end{array}$ & & & & $\begin{array}{l}42.9(3 / 7) \\
57.1(4 / 7)\end{array}$ & & & \\
\hline
\end{tabular}

After the first treatment with AyuFertin the number of small and medium follicles decreased, while the number of large follicles increased (Figure S2). Two experimental animals exhibited estrus and were served by the bull. In five animals treated repeatedly, 
the number of small and medium follicles increased. Large follicles and corpora lutea were found in these animals in $80 \%$ and $60 \%$, respectively (Table 5).

After the second treatment, three non-mated animals from the experimental group exhibited estrus and were served by the bull. In the other two animals, despite the determination of the large follicles with a size of 11-12.6 mm, no exhibition of estrus was detected. The resumption of cyclic ovarian activity in these animals was confirmed by the detection of corpora lutea during a later examination. In total, by ultrasound examination on the 70th day postpartum, three animals from the experimental group and one from the control group were diagnosed as pregnant (Figure S3).

During the control ultrasound examination, on the 90th day, one more pregnancy was found in the experimental group. Further analysis showed that all registered pregnancies in both groups (5/13) were in multiparous animals, while the pregnancies in primiparous and second-parity animals were not identified (Table 6).

Table 6. Comparative analysis of the biometric parameters and established pregnancies between the control and experimental groups.

\begin{tabular}{|c|c|c|c|c|c|c|c|}
\hline Parameters & \multicolumn{3}{|c|}{ Control Group $(n=6)$} & \multicolumn{3}{|c|}{ Experimental Group $(n=7)$} & $\begin{array}{c}p \text {-Value } \\
\text { between Groups }\end{array}$ \\
\hline Calving period & \multirow{2}{*}{\multicolumn{3}{|c|}{$\begin{array}{c}14 \text { March-22 April } 2019 \\
7 \pm 2.4\end{array}$}} & \multicolumn{3}{|c|}{29 March-29 April 2019} & \\
\hline Average age (years) & & & & \multirow{2}{*}{\multicolumn{3}{|c|}{$\begin{array}{c}6.6 \pm 2.3 \\
577.1 \pm 15.1\end{array}$}} & NS \\
\hline $\begin{array}{l}\text { Average body } \\
\text { weight }(\mathrm{kg})\end{array}$ & \multicolumn{3}{|c|}{$583.3 \pm 18.9$} & & & & NS \\
\hline $\begin{array}{l}\text { Average number of } \\
\text { lactations }\end{array}$ & \multicolumn{3}{|c|}{$3.8 \pm 1.79$} & \multicolumn{3}{|c|}{$3.4 \pm 2.07$} & NS \\
\hline \multirow{3}{*}{ Parity } & $\mathrm{PP}$ & SP & MP & PP & SP & MP & \\
\hline & $1 / 6$ & $1 / 6$ & $4 / 6$ & $2 / 7$ & $1 / 7$ & $4 / 7$ & NS for all \\
\hline & $0 / 1$ & $0 / 1$ & $1 / 4$ & $0 / 2$ & $0 / 1$ & $4 / 4$ & \\
\hline \multirow[t]{2}{*}{ Pregnancies } & PP vs. MP & SP vs. MP & $\begin{array}{l}\mathrm{PP}+\mathrm{SP} \\
\text { vs.MP }\end{array}$ & PP vs. MP & SP vs. MP & $\mathrm{PP}+\mathrm{SP}$ vs. MP & 0.04 for MP \\
\hline & $p=0.61$ & $p=0.61$ & $p=0.47$ & $p=0.02$ & $p=0.04$ & $p=0.01$ & \\
\hline
\end{tabular}

$\mathrm{PP}$ - primiparous animals; $\mathrm{SP}$ - second parity animals; MP—-multiparous animals; NS—non-significant.

Moreover, the positive effect of AyuFertin for MP buffaloes led to significant differences in pregnancy rate between MP and PP and SP buffaloes in the experimental group as well as between MP of experimental and MP of control animals (Table 6).

\section{Discussion}

The present study demonstrated a positive effect after early administration of the herbal supplement AyuFertin for overcoming the postpartum anestrus and shortening the intercalving period in Bulgarian Murrah buffaloes. The treatment with AyuFertin not only stimulated follicle growth and led to successful ovulation, but also increased the pregnancy rate in the treated group of animals by $40.5 \%$ compared to the controls within 70 days after calving. Four buffalo-calves were born within one year of calving (calving interval $362.7 \pm 6.21$ days) in the experimental group compared to only one in the control group.

No adverse effect of AyuFertin on the basic biochemical parameters in the blood serum of the supplemented animals was found. All post-treatment values, including the deviations in cholesterol and LDH, were in the physiological range of these parameters for buffaloes [34,35].

The main active ingredients of AyuFertin are believed to be trienoic acids. However, our biochemical analysis of AyuFertin showed that linoleic is the main fatty acid to be present in the sample ( $42 \%$ versus $14.3 \%$ for trienoic acids). Linoleic acid from the group of omega- 6 is considered an essential fatty acid because animal and human bodies are unable to synthesize these compounds [36]. Several studies have reported that this essential fatty acid (EFA) serves as an in vivo precursor to arachidonic acid, whose main function is the production of prostaglandins of 2-series as PGF2 $\alpha$ and E2 with importance in mammalian reproduction [37-39]. According to Arosh et al. [40], prostaglandins biosyn- 
thesis is selectively directed toward PGF2 $\alpha$ during luteolysis and to PGE2 at the time of the establishment of pregnancy. Decreased progesterone levels in our experimental animals after treatment with AyuFertin, are likely to indirectly confirm increased PGF2 $\alpha$, which plays important role in stopping progesterone production, leading to the onset of a new estrous cycle and follicular growth [41]. Our data are supported by the results of Dirandeh et al. [39], who reported that feeding n-6 polyunsaturated fatty acids (PUFA) increases the endometrial percentages of linoleic and arachidonic acids (AA), enhances the synthesis of prostaglandin F2 $\alpha$ (PGF2 $\alpha$ ), and improves the uterine health. The advantages of the natural precursors of PGF $2 \alpha$ over the administration of a single high dose of exogenous PGF are systemic release and a lower dose of produced prostaglandin F, which more accurately reflect the physiologic amounts available during regular CL regression [42].

The fatty acid trienoic esters and alpha-linolenic acid (ALA) belonging to the n3 PUFAs group were also found in AyuFertin. Animals and humans cannot synthesize trienoic acid on their own, such as linolenic acid (9,12,15-octadecatrienoic acid), therefore it is an essential part of the diet that should be obtained from plant sources in an appropriate quantity. After ingestion, this acid is metabolized to the important eicosapentaenoic acid (EPA C20: 5) and C22 (docosahexaenoic acid, 22: 6) acids, and C20 is a precursor to 3-series prostaglandins biosynthesis [37,38]. Decreased expression of the enzyme prostaglandin F synthase (PGFS), which converts prostaglandin H2 to PGF2a, has been reported in cows fed an n-3 PUFA diet, while expression of the enzyme prostaglandin $E$ synthase (PGES), which in turn increases PGE2 synthesis, was enhanced [43,44]. Prostaglandin E2 plays a very important role during early pregnancy as a luteoprotective factor. It helps maintain CL and completely blocks the action of PGF at the CL level [41]. In addition to increasing the prostaglandin E2 synthesis, eicosapentaenoic acid (EPA,20:5) generates the less-inflammatory and less potent prostaglandin E3 (PGE3) [45], which could reduce the immunological problems of maternal pregnancy recognition. These data may explain our results, showing a high pregnancy rate $(80 \%)$ among estrus-manifesting animals in the experimental group and a $100 \%$ delivery rate.

Therefore, not just are trienoic fatty acids reported as the main active substances in many herbal heat inducers [9-11], but the n-6 FA precursors of prostaglandins are also important for the successful application of the herbal preparation for overcoming anestrus. In fact, the presence of both n-3 and n-6 PUFAs in the AyuFertin preparation in an appropriate ratio stimulated the follicular growth to the dominant follicle and preserved the pregnancy.

It should be noted that the supplementation of AyuFertin is more beneficial for the multiparous buffaloes. All animals that became pregnant have had 4-6 parities. There is evidence [46] that parity affects the postpartum to estrus interval, which is longer in PP than in MP buffaloes, but the specific effect of AyuFertin on MP buffaloes is not yet clear and further studies in representative groups of animals with different parities are needed.

A detailed biochemical analysis of AyuFertin showed that in addition to specific fatty acids, the preparation contains many other active substances with an important role in reproduction. Among the tocopherols, high levels of alfa-tocopherol, known as vitamin E, have been found in the AyuFertin. Vitamin $\mathrm{E}$ is an important component of membranes in all cells, including gametes, and functions as an antioxidant to protect cellular membranes, for example by protecting polyunsaturated fatty acids (PUFAs) from autoxidation [47,48] It also plays important role in the ovary protection against oxygen radicals during corpus luteum regression [49] and can affect fertility by improving ovulation rate and endometrial response $[50,51]$. The positive effect of vitamin $\mathrm{E}$ has been shown for buffalo oocytes in vitro. The supplementation of vitamin $\mathrm{E}$ to the culture medium increases the developmental competence of buffalo oocytes [52].

The noticeable increase of follicular growth and size established in $85.7 \%$ of the treated animals on 24d pp may also be provoked by other components of AyuFertin such as polyphenols and lutein. Some authors have reported that these substances may affect the expression of follicular growth factors as GDF9 and BMP15 leading to granulosa cell 
proliferation $[53,54]$. However, the functional maturity of granulosa cells sometimes delays, despite their intensive growth. The above-mentioned may explain our finding that not all experimental animals possessing large follicles exhibited estrus. The granulosa cells must produce a sufficient quantity of estrogens to show estrus [55]. As substances with high antioxidant and anti-inflammatory properties, polyphenols and lutein are important for maintaining the redox balance in the ovary, which is necessary for the proper oocyte development and maturation [56,57].

The aforementioned beneficial effects of alfa-tocopherol, polyphenols, and carotenoids are likely to provide additional value for the successful resumption of ovarian activity, ovulation, and fertilization of the experimental animals.

\section{Conclusions}

The supplementation of the bioactive herbal product AyuFertin from day 21 postpartum can stimulate follicular growth in the buffalo's ovary, which leads to the development of follicles with ovulatory capacity, followed by successful ovulation. With the introduction of a fertile bull in both groups, the aforementioned treatment resulted in a better pregnancy rate in the MP buffaloes from the experimental group compared to the control group. However, the mechanism of the beneficial effect of AyuFertin in multiparous buffaloes remains to be elucidated in further investigations in a larger number of animals.

Supplementary Materials: The following are available online at https:/ / www.mdpi.com/2076-261 5/11/2/420/s1, Figure S1: Small follicles in the ovaries of Bulgarian Murrah buffalo at postpartum day 20 (before treatment with AyuFertin), Figure S2: Large and medium follicles in the ovaries of Bulgarian Murrah buffalo at postpartum day 24 (after the 1st treatment with AyuFertin), Figure S3: Pregnancy in experimental Bulgarian Murrah buffalo at day postpartum 70.

Author Contributions: Conceptualization and methodology, E.K., Y.I., N.V.; investigation, Y.I., N.V., I.F., D.M., A.I., D.A., P.P., V.M.; resources, Y.I., D.M., A.I.; data curation, E.K., Y.I., S.Y.; writing—original draft preparation, E.K, D.M., P.P.; writing-review and editing, S.Y., D.M., P.P., D.A., E.K.; visualization, I.F., D.A.; supervision, E.K.; project administration, N.V.; funding acquisition, all. All authors have read and agreed to the published version of the manuscript.

Funding: The research was implemented under the National Scientific Programme "REPROBIOTECH" (grant 0406-105) funded by the Ministry of Education and Science of Bulgaria.

Institutional Review Board Statement: The experimental work with animals on the farm was approved by the Bulgarian National Animal Ethics commission in accordance with the Bulgarian Veterinary Law (25 January 2011) regarding the living conditions and welfare of livestock animals used for experimental purposes, which is adapted to the European Union regulation 86/609 (AF 9747A-0002/N1430 from 05 April 2018).

Data Availability Statement: All data are included in the present article and its Supplementary Materials.

Acknowledgments: AyuFertin, provided by "Indian Herbs Specialities Pvt. Ltd" as a gift, is gratefully acknowledged.

Conflicts of Interest: The authors declare no conflict of interest.

\section{References}

1. Baruselli, P.S.; Carvalho, N.A.T. Biotechnology of reproduction in buffalo (Bubalus bubalis). Rev. Bras. Reprod. Anim. 2005, $29,4-17$.

2. Balamurugan, B.; Karuthadurai, T.; Ramamoorthy, M.; Dayanidhi, J. Manipulation of Estrous Cycle to Improve Reproductive Efficiency in Cattle and Buffalo. Int. J. Livestock Res. 2017, 8, 19-31.

3. De Rensis, F.; López-Gatius, F. Protocols for synchronizing estrus and ovulation in buffalo (Bubalus bubalis): A review. Theriogenology 2007, 67, 209-216. [CrossRef]

4. Dhaliwal, G.S.; Murray, R.; Woldehiwet, Z. Some aspects of immunology of the bovine uterus related to treatments for endometritis. Anim. Reprod. Sci. 2001, 67, 135-152. [CrossRef]

5. Snoj, T.; Majdič, G. Mechanisms in endocrinology: Estrogens in consumer milk: Is there a risk to human reproductive health? Eur. J. Endocrinol. 2018, 179, 275-286. [CrossRef]

6. Ganmaa, D.; Sato, A. The possible role of female sex hormones in milk from pregnant cows in the development of breast, ovarian and corpus uteri cancers. Med. Hypotheses. 2005, 65, 1028-1037. [CrossRef] 
7. Gupta, R.; Thakur, M.S.; Shrivastava, O.P.; Pandey, N. Comparison of hormonal and homeopathic complexes for treatment of true anestrus in post-partum buffaloes during the summer. Buffalo Bul. 2011, 30, 30-33.

8. Samad, M.A.; Hasan, M. Clinical use of Prajana and Banjhana in anestrous buffaloes of Bahgladesh. Bangladesh Vet. 1984, 1, 9-11.

9. Hussain, J.; Bhat, A.S.; Shaheen, M.; Islam, R. Comparative response of vitamin-mineral vs. herbal therapy in alleviatinh post-partum true anestrum in dairy cows. Indian J. Anim. Res. 2009, 43, 222-223.

10. Tanwar, P.S.; Rathore, S.S. Comparative evaluation of the mineral-vitamin combination (CalFos AD3Plus) and herbal heat inducer (Prajana HS) in their responses to oestrus induction and conception in rural postpartum anestrous buffaloes in semi-arid region of Rajasthan. Anim. Sci. Rep. 2015, 9, 28-32.

11. Chaudhiry, V.; Kumar, A.; Mohan, G.; Verma, R.; Srivastava, S. The study of therapeutic efficacy of mineral mixture, herbal and ethno veterinary medicine on anoestrus buffalo heifers. Indian J. Anim. Res. 2019, 53, 1639-1644. [CrossRef]

12. Kabir, K.K.; Rawal, C.V.S.; Ansari, M.R.; Varshney, J.P.; Srivastava, R.S. Comparative efficacy of herbal preparations in the management of anoestrus in non-descript rural buffaloes. Indian J. Anim. Reprod. 2001, 22, 143-145.

13. Dutt, R.; Mehrotra, S.; Shanker, U.; Singh, G. Effect of Murraya koenigii and Aegle marmelos feeding on anestrus buffaloes. Indian J. Anim. Reprod. 2011, 32, 47-49.

14. McCracken, J.A. Prostaglandins and leukotrienes. In Endocrinology: Basic and Clinical Principles; Humana Press: Totowa, NJ, USA, 2005; pp. 93-111.

15. Kindahl, H.; Frederickson, G.; Madej, A.; Edqvist, L.E. Role of prostaglandins in uterine involution. Proc. Xth Int. Cong. Anim. Reprod. AI 1984, 9-24.

16. Lohan, I.S.; Malik, R.K.; Kaker, M.L. Uterine involution and ovarian follicular growth during early postpartum period of Murrah buffaloes. Asian-Aust. J. Anim. Sci. 2004, 17, 313-316. [CrossRef]

17. Young, I.M.; Anderson, D.B. Plenderleith RWJ: Increased conception rate in dairy cows after early postpartum administration of prostaglandin F2 $\alpha$ THAM. Vet. Rec. 1984, 115, 429-431. [CrossRef]

18. Iqbal, S.; Allem, M.; Saaed, M.A. Role of single injection of prostaglandin F2 alfa on breeding efficiency of postpartum buffaloes. Pakistan Vet. J. 2003, 23, 197-201.

19. Yotov, S.; Atanasov, A.; Ilieva, Y. Induction of ovarian activity in Bulgarian Murrah buffaloes by hormonal treatment in early postpartum period. Asian Pac. J. Reprod. 2013, 2, 93-98. [CrossRef]

20. Shahrajabian, M.H.; Sun, W.; Cheng, Q. Clinical aspects and health benefits of ginger (Zingiberofficinale) in both traditional Chinese medicine and modern industry, Acta Agriculturae Scandinavica, Section B. Soil Plant. Sci. 2019, 69, 546-556.

21. Limem, S.; Banlipo, D.; Karmous, T. Phytochemical Composition and Antioxidant Power of Citrullus colcynthis from Togo. Int. J. Pharm. Phytochem. Res. 2016, 8, 531-536.

22. Oforma, C.C.; Udourioh, G.A.; Ojinnaka, C.M. Characterization of Essential Oils and Fatty Acids Composition of Stored Ginger (Zingiber officinale Roscoe). J. Appl. Sci. Environ. Manag. 2019, 23, 2231-2238. [CrossRef]

23. Georgieva, L.; Marchev, A.; Ivanov, I.; Ganeva, D.; Bojinov, B.; Pavlov, A. Improved HPLC methods for determination of carotenoids and tocopherols in different varieties of tomatoes. Sci. Works 2013, 60, 632-637.

24. Mihaylova, D.; Vrancheva, R.; Petkova, N.; Ognyanov, M.; Desseva, I.; Ivanov, I.; Popova, M.; Popova, A. Carotenoids, tocopherols, organic acids, charbohydrate and mineral content in different medicinal plant extracts. Zeitschrift für Naturforschung 2018, 73, 439448. [CrossRef]

25. Kujala, S.; Loponen, M.; Klika, D.; Pihlaja, K. Phenolics and betacyanins in red beetroot (Beta vulgaris) root: Distribution and effect of cold storage on the content of total phenolics and three individual compounds. J. Agric. Food Chem. 2000, 8, 5338-5442. [CrossRef] [PubMed]

26. Mihaylova, D.; Lante, A.; Krastanov, A. Total phenolic content, antioxidant and antimicrobial activity of Haberlea rhodopensis extracts obtained by pressurized liquid extraction. Acta Aliment. 2015, 44, 326-332. [CrossRef]

27. Brand-Williams, W.; Cuvelier, M.E.; Berset, C. Use of a free radical method to evaluate antioxidant activity. LWT Food Sci. Technol. 1995, 28, 25-30. [CrossRef]

28. Re, R.; Pellegrini, N.; Proteggente, A.; Pannala, A.; Yang, M.; Rice Evans, C. Antioxidant activity applying an improved ABTS radical cation decolorization assay. Free Radic. Biol. Med. 1999, 26, 1231-1237. [CrossRef]

29. Benzie, I.F.; Strain, J.J. Ferric reducing/antioxidant power assay: Direct measure of total antioxidant activity of biological fluids and modified version for simultaneous measurement of total antioxidant power and ascorbic acid concentration. Methods Enzymol. 1999, 299, 15-27. [CrossRef]

30. Apak, R.; Güçlü, K.; Özyürek, M.; Karademir, S.E. Novel total antioxidant capacity index for dietary polyphenols, vitamin C and E, using their cupric ion reducing capability in the presence of neocuproine: CUPRAC method. J. Agric. Food Chem. 2004, 52, 7970-7981. [CrossRef]

31. AOAC. AOAC. AOAC Official Method 920.39 Fat (crude) or ether extraction in animal feed. In AOAC Official Methods of Analysis, 18th ed.; AOAC International: Gaithersburg, MD, USA, 2012.

32. ISO. ISO12966-2:2017 Animal and Vegetable Fats and Oils—Gas. Chromatography of Fatty Acid Methyl Esters—Part. 2: Preparation of Methyl Esters of Fatty Acids; International Organization for Standardization: Geneve, Switzerland, 2017; Available online: https:/ / www.sis.se/api/document/preview/921698/ (accessed on 20 February 2019).

33. Campbell, I. Chi-squared and Fisher-Irwin tests of two-by-two tables with small sample recommendations. Stat. Med. 2007, 26, 3661-3675. [CrossRef] 
34. Latimer, K.S. Duncan and Prasse's Veterinary Laboratory Medicine. In Clinical Pathology, 5th ed.; Wiley-Blackwell: Hoboken, NJ, USA, 2011.

35. Abd Ellah, M.R.; Hamed Maha, I.; Derar, R.I. Serum biochemical and hematological reference values for lactating buffaloes. Comp . Clin. Pathol. 2014, 23, 1179-1188. [CrossRef]

36. Svahn, J.C.; Feldl, F.; Raiha, N.C.; Koletzko, B.; Axelsson, I.E. Different quantities and quality of fat in milk products given to young children: Effects on long chain polyunsaturated fatty acids and trans fatty acids in plasma. Acta Pediatr. 2002, 91, 20-29. [CrossRef]

37. Gunstone, F.D. Fatty acids: Gamma- linolenic acid. In Encyclopedia of Food Sciences and Nutrition, 2nd ed.; Academic press: New York, NY, USA, 2003; pp. 2308-2311. [CrossRef]

38. Mattos, R.; Staples, C.R.; Arteche, A.; Wiltbank, M.C.; Diaz, F.J.; Jenkins, T.C.; Thatcher, W.W. The effects of feeding fish oil on uterine secretion of PGF2alpha, milk composition, and metabolic status of periparturient Holstein cows. J. Dairy Sci. 2004, 87, 921-932. [CrossRef]

39. Dirandeh, E.; Towhidi, A.; Ansari Pirsaraei, Z.; Saberifar, T.; Akhlaghi, A.; Rezaei Roodbari, A. The endometrial expression of prostaglandin cascade components in lactating dairy cows fed different polyunsaturated fatty acids. Theriogenology 2015, 83, 206-212. [CrossRef] [PubMed]

40. Arosh Joe, A.; Sakhila, K.; Banu, J.; McCracken, A. Novel concepts on the role of prostaglandins on luteal maintenance and maternal recognition and establishment of pregnancy in ruminants. J. Dairy Sci. 2016, 99, 5926-5940. [CrossRef]

41. Wiltbank, M.C.; Mezera, M.A.; Toledo, M.Z.; Drum, J.N.; Baez, G.M.; García-Guerra, A.; Sartori, R. Physiological mechanisms involved in maintaining the corpus luteum during the first two months of pregnancy. Anim. Reprod. 2018, 15, 805-821. [CrossRef]

42. Ginther, O.J.; Araujo, R.R.; Palhao, M.P.; Rodrigues, B.L.; Beg, M.A. Necessity of sequential pulses of prostaglandin F2alpha for complete physiologic luteolysis in cattle. Biol. Reprod. 2009, 80, 641-648. [CrossRef] [PubMed]

43. Lindstrom, T.; Bennett, P. Transcriptional regulation of genes for enzymes of the prostaglandin biosynthetic pathway. Prostaglandins Leukot Essent Fatty Acids 2004, 70, 115-135. [CrossRef] [PubMed]

44. Coyne, G.S.; Kenny, D.A.; Childs, S.; Sreenan, J.M.; Waters, S.M. Dietary n-3polyunsaturated fatty acids alter the expression of genes involved in prostaglandin biosynthesis in the bovine uterus. Theriogenology 2008, 70, 772-782. [CrossRef] [PubMed]

45. Siriwardhana, N.; Kalupahana, N.S.; Moustaid-Moussa, N. Health Benefits of n-3 polyunsaturated fatty acids: Eicosapentaenoic acid and docosahexaenoic acid. Adv. Food Nutr. Res. 2012, 65, 211-222. [CrossRef]

46. Hafez, B.; Hafez, E.S.E. Reproduction in Farm. Animals, 7th ed.; Lippincott Williams and Wilkins: Baltimore, MD, USA, 2000.

47. Bjorneboe, A.; Bjorneboe, G.E.; Drevon, C.A. Ab-sorption, transport and distribution of vitamin E. J. Nutr. 1990, $120,233$. [CrossRef]

48. Pinelli-Saavedra, A. Vitamin E in immunity and repro-ductive performance in pigs. Reprod. Nutr. Dev. 2003, 43, 397-408. [CrossRef]

49. Chew, B.P. The influence of vitamins on repro-duction in pigs. In Recent Advances in Animal Nutrition; Garnsworithy, P.C., Cole, D.J.A., Eds.; Nottingham University Press: Nottingham, UK, 1995; pp. 223-237.

50. Tarin, J.; Ten, J.; Vendrell, F.J.; de Oliveira, M.N.; Cano, A. Effects of maternal ageing and dietary antioxidant supplementation on ovulation, fertilization and embryo development invitro in the mouse. Reprod. Nutr. Dev. 1998, 38, 499-508. [CrossRef] [PubMed]

51. Mohd Mutalip, S.S.; Ab-Rahim, S.; Rajikin, M.H. Vitamin E as an Antioxidant in Female Reproductive Health. Antioxidants 2018, 7, 22. [CrossRef]

52. Thiyagarajan, B.; Valivittan, K. Ameliorating effect of vitamin E on in vitro development of preimplantation buffalo embryos. J. Assist. Reprod. Genet. 2009, 26, 217-225. [CrossRef]

53. Abadjieva, D.; Kistanova, E. Tribulus terrestris Alters the Expression of Growth Differentiation Factor 9 and Bone Morphogenetic Protein 15 in Rabbit Ovaries of Mothers and F1 Female Offspring. PLoS ONE 2016, 11. [CrossRef] [PubMed]

54. Abadjieva, D.V.; Nedeva, R.; Marchev, Y.; Jordanova, G.; Chervenkov, M.; Dineva, J.; Shumkis, A.; Shimkine, A.; Teerds, K.; Kistanova, E. Arthrospira (Spirulina) platensis supplementation affects folliculogenesis, progesterone and ghrelin levels in fattening pre-pubertal gilts. J. Appl. Phycol. 2018, 30, 445-452. [CrossRef]

55. Perry, G.A.; Swanson, O.L.; Larimore, E.L.; Perry, B.L.; Djira, G.D.; Cushman, R.A. Relationship of follicle size and concentrations of estradiol among cows exhibiting or not exhibiting estrus during a fixed-time AI protocol. Domest. Anim. Endocrinol. 2014, 48, 15-20. [CrossRef]

56. Xu, C.Z.; Wang, H.F.; Yang, J.Y.; Wang, J.H.; Duan, Z.Y.; Wang, C.; Liu, J.X.; Lao, Y. Effects of feeding lutein on production performance, antioxidative status, and milk quality of high-yielding dairy cows. Dairy Sci. 2014, 97, 7144-7150. [CrossRef] [PubMed]

57. Hashem, N.M.; Gonzalez-Bulnes, A.; Simal-Gandara, J. Polyphenols in Farm Animals: Source of Reproductive Gain or Waste? Antioxidants 2020, 9, 1023. [CrossRef] 